\title{
Erratum: Active-Site Models of Streptococcus pyogenes Cas9 in DNA Cleavage State
}

\author{
Frontiers Production Office* \\ Frontiers Media SA, Lausanne, Switzerland
}

Keywords: Gene editing, CRISPR-Cas9, DNA cleavage mechanism, Molecular dynamics, off-target effects

\section{An Erratum on}

Active-Site Models of Streptococcus pyogenes Cas9 in DNA Cleavage State Tang, H., Yuan, H., Du, W, Li, G, Xue, D., and Huang, Q. (2021). Front. Mol. Biosci. 8:653262. doi: 10.3389/fmolb.2021.653262

\section{OPEN ACCESS}

Approved by: Frontiers Editorial Office, Frontiers Media SA, Switzerland

${ }^{*}$ Correspondence: Frontiers Production Office production.office@frontiersin.org

Specialty section: This article was submitted to

Structural Biology,

a section of the journal

Frontiers in Molecular Biosciences

Received: 02 June 2021 Accepted: 02 June 2021

Published: 18 June 2021

Citation:

Frontiers Production Office (2021)

Erratum: Active-Site Models of Streptococcus pyogenes Cas9 in DNA

Cleavage State.

Front. Mol. Biosci. 8:719327. doi: 10.3389/fmolb.2021.719327
Due to a production error, the second sentence in the abstract was replaced with the definition of $\mathrm{HNH}$. A correction has been made to the section.

Abstract:

"CRISPR-Cas9 is a powerful tool for target genome editing in living cells. Significant advances have been made to understand how this system cleaves target DNA. However, due to difficulty in determining active CRISPR-Cas9 structure in DNA cleavage state by X-ray and cryo-EM, it remains uncertain how the HNH and RuvC nuclease domains in CRISPR-Cas9 split the DNA phosphodiester bonds with metal ions and water molecules. Therefore, based on one- and two-metal-ion mechanisms, homology modeling and molecular dynamics simulation (MD) are suitable tools for building an atomic model of Cas9 in the DNA cleavage state. Here, by modeling and MD, we presented an atomic model of SpCas9-sgRNA-DNA complex with the cleavage state. This model shows that the $\mathrm{HNH}$ and RuvC conformations resemble their DNA cleavage state where the activesites in the complex coordinate with DNA, Mg2+ ions and water. Among them, residues D10, E762, H983 and D986 locate at the first shell of the RuvC active-site and interact with the ions directly, residues $\mathrm{H} 982$ or/and H985 are general (Lewis) bases, and the coordinated water is located at the positions for nucleophilic attack of the scissile phosphate. Meanwhile, this catalytic model led us to engineer new SpCas9 variant (SpCas9-H982A + H983D) with reduced off-target effects. Thus, our study provides new mechanistic insights into the CRISPR-Cas9 system in the DNA cleavage state, and offers useful guidance for engineering new CRISPR-Cas9 editing systems with improved specificity."

The authors apologize for this error and state that this does not change the scientific conclusions of the article in any way. The original article has been updated.

Copyright (c) 2021 Office. This is an open-access article distributed under the terms of the Creative Commons Attribution License (CC BY). The use, distribution or reproduction in other forums is permitted, provided the original author(s) and the copyright owner(s) are credited and that the original publication in this journal is cited, in accordance with accepted academic practice. No use, distribution or reproduction is permitted which does not comply with these terms. 